\title{
A DESCOBERTA DA REPRESENTAÇÃO: FIGURAS DO DISCURSO RETÓRICO NA CARTA DO ACHAMENTO DE PERO VAZ DE CAMINHA
}

THE DISCOVERY OF REPRESENTATION:

FIGURES OF RHETORICAL DISCOURSE IN

PERO VAZ DE CAMINHA'S CARTA DO ACHAMENTO

Vincenzo Arsillo*

\section{RESUMO}

A partir da análise de algumas imagens figurais e retóricas que recorrem no texto Caminha, se esboça uma interpretação semiótico-icônica da Carta do achamento.

PALAVRAS-CHAVE: Carta do achamento; figuras retóricas; conquista do Brasil.

\begin{abstract}
Moving from the analysis of some figural and rhetorical images in the Caminha's text, the essay defines a semiotic-iconic interpretation of Carta do achamento.
\end{abstract}

KEYWORDS: Carta do achamento; rhetorical figures; conquest of Brazil. 


\section{LIMINA}

A condição, o estatuto de texto "privado" - de texto, portanto, que não é concebido e não se apresenta como relato oficial de viagem para enviar ao soberano, mas, mesmo na oficialidade que qualquer escrito dirigido ao rei impunha, como petitio individual - confere à Carta do achamento de Pero Vaz de Caminha algumas marcas e características que fornecem, numa perspectiva que tente analisar a relação entre construção retórico-simbólica do texto e retórica do imaginário que o sustenta, a possibilidade de evidenciar de que modo a finalidade interna da tessitura textual revela e define tanto o tipo de percepção que a determina, como a realidade que procura descrever, o mundo "novo" que se apresenta ao olhar dos navegantes da expedição de Pedro Álvares Cabral.

A condição privada do texto, portanto, ligada indissoluvelmente à da percepção liminar ${ }^{2}$ da realidade que descreve e da "natureza" que a constitui, evidencia assim, precisamente em seu apresentar-se como relação individual, seu caráter de texto mimético, mas de uma mimese que, nascida de uma finalidade heterodirigida - o pedido de graça para Jorge de Osório, genro do autor - mostra, com um grau de evidência possível, talvez, apenas numa leitura a posteriori, em que medida e de que forma os processos lógico-retóricos internos ao texto definem uma possível e diferente percepção do outro. Assim, embora a Carta não apresente características ou usos retóricos de especial relevo ou complicação, será possível afirmar que mesmo na sua simplicidade compositiva, na sua clareza de construção, no estar fundada num esquema que faz da evidência a sua característica mais marcada, devem ser identificadas as causas da determinante relevância que o texto assumiu: ele é, sim, um dos textos "primigênios"3 sobre o Brasil, ou, aliás, sobre aquela terra que tomará o nome de Brasil, mas também é um texto "conclusivo" na sua intenção nomenclatória, ao apresentar de modo exemplar a relação heurístico-literária entre simulação e dissimulação. E, possivelmente, mesmo da sua simulação, o pedido de graça, nasce a possibilidade da total dissimulação, ou seja, neste caso, da dissimulação como maior aderência à realidade, e a uma realidade totalmente "nova" e, sobretudo, não esperada. Não se afirma, repare-se, que o discurso e a narração da Carta são "verdadeiros" em virtude da finalidade, manifesta, de captatio benevolentiae, mas antes que esta finalidade interna ao texto confere à narração e à sua construção retórica, paradoxalmente, um menor condicionamento simulatório, uma aderência maior à realidade descrita. Daí surge, também, a atitude por parte de Caminha de referir na relação apenas o que realmente viu, aquilo a que assistiu pessoalmente, o que fisicamente o seu olhar tocou 4 .

A estratégia retórica subjacente a esta linha interpretativa do "real novo" fundar-se-á, portanto, numa espécie de lógica de-negativa, em que a abordagem cognoscitiva se baseia numa constante negação de propriedade do objeto, dos indígenas como seres vivos e ainda não como seres humanos, negação que é constantemente esvaziada de sentido negativo, 
constantemente atenuada e assimilada numa visão concessiva face aos comportamentos e aos atos dos "índios", uma visão que torne conhecido o desconhecido, descritível o informe, familiar o que nos é estranho: da mesma forma, portanto, como se denota a ausência das qualidades próprias do homem "cívico", ausência que determina a principal e mais imediata diversidade e disformidade em relação ao modelo, necessariamente europeu, do narrador, é, ao mesmo tempo, posto em destaque como é possível achar um terreno comum de comunicação (que visa sempre à submissão, lembre-se, que nunca é e nunca pretende ser senão forma de submissão), de troca lógico-gestual, se não propriamente verbal ou linguística, e que poderia ser sinal da hipotética "conformidade" e pertença dos indígenas ao gênero humano. É justamente nesta tensão lógico-cognoscitiva de uma aproximação negativa, do processo de tornar conhecido e familiar o que não se conhece, através de contínuas afirmações negativas, negações que, porém, não afastam, mas aproximam o objeto a descrever, tornando, com efeito, o diferente de em parecido com, nesta constante tensão entre atração, casualidade e intencionalidade, que se constroem e encontram fundamentação as figuras ${ }^{5}$ basilares do discurso retórico da Carta.

\section{FIGURAS E CORRESPONDÊNCIAS}

A construção do texto de Caminha, como se referiu, segue um esquema clássico e paradigmático: com efeito, do exórdio ${ }^{6}$, cuja fórmula decalca estilemas tradicionais, deverá ser notado, em primeiro lugar, o uso dos tempos verbais, em que a relação entre o futuro e as formas potenciais está, na realidade, toda orientada para o destaque das novidades do presente, do acontecer no presente de um evento inesperado. E assim a condição concessiva com que se abre o texto, "posto queo capitam moor desta vossa frota e asy os outros capitaães screpuam a vossa alteza anoua do achamento desta vossa terra noua que se ora neesta nauegaçam achou" (UNALI, 1984, p. 61$)^{7}$, está entretecida de repetições e remissões constantes, que reforçam tanto o sentimento de submissão, como, através de correspondências internas, o valor do ato de contar o que se viu. Note-se, por exemplo, a relação entre "desta vossa frota" e "desta vossa terra" (esta é uma fórmula que se volta a encontrar, com uma significativa quebra, na despedida final), assim como as repetições amplificativas "anoua", "achamento", "noua", "achou”, ou o efeito de queda no presente causado pelo advérbio "ora”. Bem como ao presente da visão, como já se notou, é de atribuir o intento de referir, sem amplificações aumentativas ou depreciativas, "por afremosentar nem afear aja aquy de poer mais caaquilo que vy e me pareçeo" $(C d A, \text { p. } 61)^{8}$, o que se viu ou percepcionou.

A dimensão narrativa, além disso, apresenta-se imediatamente linear, paratática: o regular decorrer do tempo, a sucessão cronologicamente regular, o suceder-se dos dias é seguido e acompanhado de uma narração regular dos fatos. Esta correspondência é um elemento extremamente re- 
levante para os fins da estratégia retórica de uma narração "testemunhal", porque exalta e dá corpo, simultaneamente, tanto à dimensão cronológica como envolvente dos eventos, quanto à dimensão verbal como correspectiva, como função correlativa dos eventos que se narram.

E aaquarta feira segujmte pola manhãa topamos aves aque chamã fura buchos e neeste dia aoras de bespera ouuemos vjsta de tera s. premeiramente dhuu gramde monte muy alto. e rredondo e doutras serras mai baixas ao sul dele de trra chaã com grandes aruoredos. ao qual monte alto ocapitam pos nome omonte pascoal E aatera atera da vera cruz. (CdA, p. 61)

O elemento temporal não é apenas importante e determinante do ponto de vista quantitativo, mas também, e sobretudo, do ponto de vista qualitativo: é assim que se cria a primeira correspondência entre tempo simbólico e terra achada, mediante o ato clássico de nomear a terra descoberta com o nome do dia ou do período em que a descoberta se dá. O fato de denominar o monte "pascoal" e a terra "vera cruz" realiza, portanto, um duplo ato simbólico: o primeiro ligado à imagem da Páscoa como momento de passagem (como denota também a etimologia do termo), passagem que se concretizará numa abordagem igualmente simbólica e figural com a sucessiva celebração da missa; o segundo relacionado com a imagem da terra, que sempre tem um valor soteriológico, um valor de fim da instabilidade: por isso a cruz representa quer um símbolo de reconhecimento e de apropriação, quer a antecipação simbólica da função religiosa que, na "respeitosa" visão de Caminha como súbdito, cabe à coroa e à sua ação, ou seja, a evangelização. Por isso, pode-se afirmar que a denominação do monte e da terra tem uma função de antecipação simbólica e semântica do ato de conquista e de apropriação, de prolepse, tanto face à narração em si quanto em relação à finalidade narrativa do texto.

E aaquimta feira pola manhaã fezemos vella e segujmos dirtos aaterra eos naujos pequenos diãte himdo per xbij xbj xb xiiij xiij xij x. e ix [dezassete, dezasseis, quinze, catorze, treze, doze, dez e nove] braças ataa mea legoa de trra omde todos lancamos amcoras em dir $^{\text {to }}$ daboca dhuu rrio e chegariamos aesta amcorajem aas $\mathrm{x}$ oras pouco mais ou menos e daly oouemos vista dhomees q andauam pela praya obra de bij ou biij [sete ou oito] seg $^{\circ}$ os naujos pequenos diseram por chegarem primeiro. (CdA, p. 62)

Do mesmo modo, o processo de aproximação à terra estrutura-se segundo uma constante figura de progressão, que se funda especialmente na atitude, na visão "mensural" do autor, que liga sempre o dado informativo ou técnico (a distância, o número, a quantidade) a um clímax de aproximação ao objeto. O efeito, portanto, será o de conferir à sucessão dos eventos e dos objetos descritos uma espécie de dramatização quantitativa, isto é, um ato que, de uma maneira muito simples e elementar, une a dimensão do contato e da aproximação àquela progressiva do conheci- 
mento e da descoberta. E será precisamente nesta perspectiva, ainda, que à sequência lógico-cronológica do avistamento, da subsequente nomeação e do conclusivo contato - que envolvem, repare-se, as três faculdades visual, verbal e tátil -, se une a representação de uma outra progressão significativa: a da terra como evidência, da terra como propriedade (a natureza), da terra como presença (os homens). "[...] homees pardos todos nuus sem nhuua cousa que lhes cobrisse suas vergonhas. traziam arcos nas maãs esuas seetas. vijnham todos rrijos perao batel e nicolaao coelho lhes fez sinal que posesem os arcos. e eles os poseram" ( $C d A$, p. 62): a nudez é a primeira evidência, a característica principal que, inevitavelmente, impressiona o olhar dos europeus. Mas a nudez é representada, iniciando, desta forma, subliminarmente aquele processo retórico-cognoscitivo que liga a negação a uma possível assimilação, como ausência de qualidade e não como uma presença da mesma, como uma falta, não como um atributo. Esta representação negativa revela-se também a nível fônico-lexical, com a fortíssima aliteração "nuus sem nhuua cousa", que amplifica ainda mais o sentido de subtração e de essencialização negativa da nudez, colocando-a, desse modo, numa perspectiva de forte nexo lógico com a atitude de compreensão e obediência imediatamente sucessiva. À subtração negativa da nudez corresponde, de fato, uma imediata correspondência entre signo e sentido (que, na perspectiva dos conquistadores, era sempre e de qualquer forma uma correspondência entre signo e comando): a desorientação causada pela nudez é superada, é moderada e tornada assimilável pela possibilidade de uma correspondência lógica com os interlocutores indígenas.

Aly nom pode deles auer fala ne entedimento que aproueitasse polo mar quebrar na costa. Sooemnte deulhes huu barete vermelho e huua carapuça de linho que leuaua na cabeça e huu sombreiro preto. E huu deles lhe deu huu sombreiro de penas daues compridas cõ huua copezinha pequena de penas vermelhas epardas coma de papagayo e outro lhe deu huu rramal grande de comtinhas brancas meudas que querem parecer daljaueira as quaaes peças creo queo capitam manda avossa alteza e com jsto se volueo aas naaos por seer tarde e nom poder deles auer mais fala por aazo do mar. (CdA, p. 62)

O primeiro contato é emoldurado por um elemento natural fortíssimo, em todos os sentidos: o fragor do mar ("nom pode deles auer fala ne entedimento que aproueitasse polo mar quebrar na costa"; "nom poder deles auer mais fala por aazo do mar"). É importante que a cena do primeiro contato seja inserida num quadro que contribui para a sua dramatização e que exalta a sua exemplaridade. A cena é circunscrita e cenicamente notável: é o barulho, o fragor, ou seja, a voz do elemento marinho (isto é, de um elemento natural) que impede a compreensão das vozes humanas, o entendimento entre as vozes. A narração também recorre a outra figura, ela também basilar e tradicional nos relatos e nas relações, ou seja, a enumeração $0^{9}$. A ela sempre se prende uma visão nomenclatória de caráter su- 
perficial, mas não indiferente ou distraída; Caminha tenta sempre dar uma conotação ao objeto que descreve seguindo o já aludido procedimento de reductio ad notum, fundado num constante processo de deslizamento para o semelhante. Daí procede a numerosa e estratégica presença dos termos "como" ou "parecer", que resolvem a visão num contexto progressivamente assimilável, embora, depois, remetam sempre para uma visão direta do objeto, que se transformará, à medida que o texto se desenrola, numa verdadeira exortação à planificação de um conhecimento mais aprofundado e sistemático

A relação entre lógica negativa e comparação assimilativa é, não por um acaso, evidente na segunda descrição (na realidade, a primeira circunstanciada) dos indígenas - "afeiçam deles he seerem pardos maneira dauermelhados de boõs rrostros e boos narizes bem feitos. amdam nuus sem nenhuua cubertura, nem estimam nhuua coussa cobrir nem mostrar suas vergonhas. e estam açerqua disso com tanta jnocemçia como teem em mostrar orrostro [...]" (CdA, p. 63) -, na qual a sequência das figuras é absolutamente linear e evidente: assim, à conotação e à descrição positi$v a$, àlgumas sumárias indicações sobre traços somáticos e a notação que "amdam nuus" (reforçada pela especificação "sem nenhuua cubertura"), segue-se a conotação negativa, "nem estimam nhuua coussa cobrir nem mostrar suas vergonhas", a que se acrescenta, por fim, a conotação comparativa, de igualdade e, logo, de assimilação, "e estam açerqua disso com tanta jnocemçia como teem em mostrar orrostro".

Ocapitam quando eles vieram estava asentado em huua cadeira e huua alcatifa aos pees por estrado e bem estido cõ huu colar douro muy grande ao pescoço. e sancho de toar e simam de miranda enjcolaao coelho e aires corea e nos outros que aquy na naao cõ ele himos asentados no chaão per esa alcatifa. acemderam tochas e emtraram e nõ fezeram nhuua mençam de cortesia nem de falar ao capitam nem anjmguem. pero huu deles pos olho no colar do capitam e começou daçenar cõ amaão pera aterra e depois perao colar como que nos dizia que avia em tera outro e tam bem vio huu castical de prata e asy meesmo acenaua peraa tera e entã perao castical como que avia tan bem prata. (CdA, p. 63-64)

Outra importante figura que aparece na Carta e que marca sempre momentos relevantes para os fins da narração é o quiasmo, que nesta passagem surge com algumas conotações semióticas extremamente claras. A construção simbólica deste quiasmo é, com efeito, a relação alto/ baixo-baixo/alto, que reforça ainda mais a imagem de concessão e domínio simbólico dos conquistadores, na primeira ocasião de contato com dois indivíduos indígenas por parte do capitão-mor e dos chefes da expedição (encontro que se dá, repare-se, num outro espaço circunscrito e definido por um pano de fundo, o espaço da nau, que por sua vez é símbolo metonímico do poder real). A descrição, portanto, desenvolve-se primeiro na direção que vai de cima para baixo, do fio de ouro ao tapete (o tapete 
onde estão sentados os capitães é um espaço comum de poder, é ele também uma figura metonímica, construindo, desse modo, a cena quase que através de um processo de miniaturização, ou, mais precisamente de mise en abyme). Através da progressão sucessiva, que se apresenta quase como uma construção antifrástica, in diminuendo (luz, entrada dos indígenas, ausência de formas rituais, naturalmente europeias), passa-se à direção de baixo para cima que, numa cena muito bem congeminada, põe em relação invertida os dois termos anteriores, com aquele "gesto semântico" que une idealmente o solo ao colar. Este também é um quadro representativo, um verdadeiro tableau, onde a estrutura visa a uma constante dramatização simbólica e retoricamente estratégica.

Na passagem imediatamente seguinte, de fato, à descrição dos indígenas, se segue uma concreta declaração das modalidades quer de interpretação de Caminha, e por conseguinte dos conquistadores, quer dos seus mecanismos de projeção:

Vio huu deles huuas contas de rrosairo brancas. acenou que lhas desem e folgou muito com elas e lancouas ao pescoço e despois tirouas e enbrulhouas no braço e acenaua peraa trra e entã peraas contas eperao colar do capitam como que dariam ouro por aquilo. Isto tomauamonos asy polo desejarmos mas se ele queria dizer que leuaria as conta e mais ocolar. jsto nom querjamonos emtender porque tho nõ aviamos de dar edespois tornou as contas aquem lhas deu[... $]^{10}(C d A$, p. 64)

Exprime-se, aqui, com clareza apodíctica, a geral condição hermenêutica dos portugueses, manifesta-se sem mediações a semiótica retórica própria da Carta do achamento: ela define um processo que chamaríamos de eufemização do real, eufemização nomenclatória e normativa, uma vez que a narração e a visão a ela subjacente descrevem a realidade "nova" não como realmente ela é, mas como se pensa, se deseja e se pretende que seja e apareça; e não é por acaso, possivelmente, que se voltam a apresentar figuras já descritas da negação e da similitude, não e assim, mas invertidas: "tomauamonos asy polo desejarmos" encontra-se, com efeito, em relação especular com "nom querjamonos emtender porque lho nõ aviamos de dar".

A dupla semântico-figural negativo/parecido encontra, depois, uma aplicação também em casos elípticos, normalmente ligados à representação da nudez e dos caracteres que a acompanham. Assim, por exemplo, na famosa passagem sobre a ausência de circuncisão ("sem teer nenhuua maneira de cobrirem suas vergonhas as quaees nõ herã fanadas”, $C d A$, p. 64), há uma relação lógica imediatamente consequencial e uma coincidência perfeita entre os dois elementos, mesmo em virtude da elipse do segundo termo; esta ausência torna-se, além disso, uma evidente prova de não pertença (neste caso, à religião judia): não eram circuncidados, logo eram como nós.

A nudez, em todo caso, é um dos elementos principais na descrição dos indígenas, e a definição desta constante apresenta-se sempre ligada a um juízo de admirada naturalidade, e ela é interpretada sempre 
como sinal tanto de simplicidade quanto de pureza: “[...] suas vergonhas tam altas e tã çaradinhas e tam limpas das cabeleiras que de as nos mujto bem olharmos nõ tijnhamos nhuua vergonha" ( $C d A$, p. 65) (há, aqui, um uso estratégico do tão, seguido do não consecutivo, ou seja, coloca-se em relação à nudez com o efeito inesperado de naturalidade que ela produz; observe-se, porém, que isso ocorre ainda no contexto de uma construção e de uma lógica negativa e eufemizante). Ao mesmo tempo, o termo "vergonha" aparece, com fácil artifício, em construções retóricas mais evidentes e intencionalmente conotadas: "e huua daquelas moças era toda timta defumdo acjma daquela timtura aqual çerto era tã bem feita e tam rredomda e sua vergonha que ela nõ tijnha tam graçiossa que amuitas molheres de nossa trra vendolhe taaes feições fezera vergonha por nom teerem asua comeela" ( $C d A$, p. 66), onde é de salientar a constante remissão entre negações e comparações, entre significante e significado, entre evidência e interpretação, entre simulação e dissimulação.

A persistência, na tessitura do texto, de imagens contidas sempre dentro de confins de temporalidade e modalidade reconhecíveis, encontra na narração uma importante figuração no ato liminar, simbólica e fisicamente liminar, enquanto realizado no "jlheeo" ( $C d A$, p. 66), da celebração da missa no dia do domingo de Pascoela. Aqui também, à função normativa e delimitativa do rito, e principalmente do rito religioso, se une a dupla moldura do pavilhão e do altar, "huu esperauel e dentro neele aleuantar altar" (CdA, 1984, p. 66), figuras quase em forma de hendíadis, que tornam o espaço sem medida, ou mais precisamente amensural, da nova terra, um espaço representativamente circunscrito e delimitado, teatralizado na sua função de cerimônia do sacro. A retórica simbólico-religiosa da missa determina, portanto, um processo de espetacularização do discurso hermenêutico e de relação com o outro; e a ritualidade da cena institui o primeiro, marcadíssimo exemplo de relação entre o ético e o estético do texto.

Note-se contudo, por exemplo, que a teatralização se realiza também a nível fônico, com a contraposição entre as vozes dissonantes e caóticas e confusas dos indígenas, um vozear que impede a troca de palavras, como anteriormente o fragor do mar, "aly por emtam nom ouue mais fala ne emtendimento cõ eles por aberberja deles seer tamanha que se nom emtendia nem ouuja njnge" ( $C d A$, p. 65), e a voz "uníssona" e salmodiante do oficiador e dos sacerdotes, "fez dizer misa aqual dise o padre frey amrique em voz entoada e oficiada cõ aquela meesma voz pelos outros padres e sacerdotes que aly todos heram" ( $C d A$, p. 66) (repare-se, também, que o texto diz "padres e sacerdotes", quase que numa hendíadis reforçativa). A missa apresenta-se, portanto, como a representação simbólica e ritual por excelência, quase heráldica, na sua essência icástica e na sua brevidade. Por isso, de fato, aos sinais do poder, e à sua demonstração e manifestação, se une sempre um estilo sóbrio, seco e conciso, uma concinnitas verbal e representativa, que é simultaneamente emblema e sentido. À mesma lógica obedece a presença contígua do capitão-mor e da bandeira, símbolo 
do reconhecimento do poder e da fé, "aly era com ocapitam abandeira de xpos" ( $C d A$, p. 66), cuja verticalidade, imagem antecipatória e metonímica da cruz, se opõe à imagem não hierarquizada e não piramidal das populações “novas", à horizontalidade indígena.

A estratégia cognoscitiva e hermenêutica, que, recorde-se, é sempre também estratégia retórica do autor e do contexto cultural a que pertence, revela-se com especial clareza na discussão, representada em discurso indireto, entre Cabral e os capitães da frota, a que assiste também Caminha (respeitando, neste caso também, a norma do "per vista e per udita"), discussão que versa sobre a oportunidade de enviar ao rei a comunicação da descoberta da nova terra e, eventualmente, dois indígenas como specimina (em troca, repare-se, de dois deportados: o aspecto edênico é apenas uma imagem, porque prevalece o lado ameaçador do lugar não conhecido). "Pregumtou [o capitão] mais se seria boo tomar aquy per força huu par destes homees. peraos mandar avosa alteza. e leixar aquy por eles outros dous destes degradados. aesto acordaram que nõ era necesareo tomar per força homees. por que jeeral costume era dos que asy leuauom per força peraalgua parte dizerem que ha hy todo oque preguntam" ( $C d A, \mathrm{p}$. 68): a esta lógica da mitificação do lugar originário, que é uma notação de relevância não banal, se junta a lógica da práxis, que une a necessidade do conhecimento à organização do domínio e da exploração; será mais conveniente, portanto, o conhecimento direto e "no local", do que o estudo de exemplares fora do seu contexto próprio. Note-se que esta atitude, natural para um olhar de hoje, representa, para Caminha e os seus contemporâneos, um ato de conquista cultural, inconsciente, talvez, porque ditado pelo desejo de domínio ligado à consubstancial desconfiança religioso-cultural europeia, mas em todo caso significativo na perspectiva de uma lógica retórica como lógica de conhecimento (a decisão tomada pelo conselho também tem um aspeto, por assim dizer, irônico: aconselha-se, de fato, a não criar dois novos deportados - tais seriam os dois indígenas - e "fecham-se" num lugar aberto, mas desconhecido e por isso ameaçador e limitante - uma "prisão aberta" - os dois deportados verdadeiros. Mas, poder-se-ia dizer, a condição dos dois deportados já estava definida anteriormente, logo a descoberta não altera o seu "estatuto").

O tema do contato com a nova realidade apresenta-se, depois, com especial valor simbólico na cena em que se descreve um momento de festa, ritualizado com danças e cantos:

[...] e aalem do rrio amdauã muitos deles damçando e folgando huus ante outros sem se tomarem pelas maãos e faziãno bem. pasouse emtan aalem do rrio diego dijz alx ${ }^{e}$ que foi de sacauem que he home gracioso edeprazer elevou comsigo huu gayteiro noso cõ sua gaitaa e meteose cõ eles adançar tomandoos pelas maãos e eles folgauam e rriam e andauam cõ ele mey bem ao soõ dagaita. despois de dançarem fezlhe aly amdando no chaão mujtas voltas ligeiras e salto rreal deque eles espantauam e rriam e folgauã muito. e com quanto os cõ aquilo muito segurou e afaagou. tomauam logo huua esqujueza coma monteses e foranse pera cjma. ( $C d A$, p. 69-70) 
É de salientar que os momentos cruciais na estratégia retórica são sempre os de passagem, os momentos intersticiais, os momentos em que um contato determina, ou pode determinar, uma mudança. Por isso, o tema da dança indígena sem o contato das mãos contraposta à portuguesa, com o contato das mãos, de mãos dadas, pode parecer um elemento secundário, mas, numa retórica da aproximação e do conhecimento, é um passo fundamental: o gesto semântico do contato, aqui ritualizado no espaço alegórico da dança, constitui, a um nível inicial e basilar, proemial, poderíamos dizer, o primeiro grau de um processo de domesticação e de submissão, ou seja, um ato que constitui uma metonímia do gesto de conquista, do gesto da posse; não é por acaso, de fato, que a desconfiança dos indígenas os faz definir, pela primeira vez no texto, "coma monteses", como animais selvagens. O processo de eufemização encontra um primeiro obstáculo que, contudo, será interpretado sucessivamente ainda num sentido positivo, mais uma vez eufemizado (confirmando, talvez, que se trata de uma atitude a priori, isto é, procedente de uma lógica finalística e não desinteressada): a desconfiança nasce de uma grande pureza, afirmará Caminha, não é um produto simulatório de uma cultura (porque, na visão inicial do conquistador, dessa forma não são consideradas as populações indígenas), mas antes, "coma monteses", um puro comportamento natural positivo, logo potencialmente domesticável e "amansável”. E, de fato, notar-se-á pouco mais adiante que "abasta que ataaquy como quer que se eles em alguua parte amansasem logo dhua maão peraaout ${ }^{\mathrm{a}}$ se esqujuauam coma pardaaes deceuadoiro e home nom lhes ousa de falar rrijo por se mais nom esqujuarem e todo se pasa como eles querem polos bem amansar"11 ( $C d A$, p. 70.). O elemento de maior destaque é, aqui, a relevância que é atribuída ao tom da voz, à modulação quantitativa da voz que é também conotação qualitativa da comunicação, ou, mais precisamente, daquele processo que se está a definir como uma comunicação auroral.

A lógica de Caminha estrutura-se sempre num duplo nível dialético de definição, segundo o qual os dois extremos, que, porém, a nível retórico-argumentativo vêm a sobrepor-se, são representados, respectivamente, pela visão do indígena com ser absolutamente natural, de uma perfeição absolutamente natural, ou seja, pura, e pela visão especular, mas não contraposta, da sua condição liminar e não identificável, por não ser nem totalmente animal nem totalmente humana. É óbvio que o elo de ligação entre estes dois aspectos será constituído, aqui também de forma não casual, pelo ato da conversão e evangelização, que é sempre, repare-se, um ato fundamentalmente retórico-linguístico ${ }^{12}$.

Estauam na praia quando chegamos obra de $\mathrm{lx}$ ou lxx [sessenta ou setenta] sem arcos e sem nada. tamto que chegamos vieramse logo peranos sem se esqujuarem. e depois acodiram mujtos que seriam bem $\mathrm{jic}^{\mathrm{c}}$ [duzentos] todos sem arcos. E mesturaramse todos tanto com nosco que nos ajudauam deles aacaretar lenha e meter nos batees e lujtauam cõ os nosos e tomauam mujto prazer. Eem quanto faziamos alenha. 
faziam dous carpenteiros huua grande cruz dhuu paao que se omtem pera ysso cortou. mujtos deles vijnham aly estar cõ os carpenteiros e creo queo faziã mais por veerem afaramenta de ferro com q afaziã q por veerem acruz por que eles nõ teem cousa que de fero seja e cortam sua mad $^{\text {ra }}$ e paaos com pedras feitas como cunhas metidas em huu paao antre duas talas muy bem atadas e per tal maneira que andam fortes seg $^{\circ}$ os homees que omtem asuas casas deziam por que lhas viram la. era ja aconuersaçam deles com nosco tanta que casy nos toruauam ao que aviamos defazer. (CdA, p. 72)

A construção desta passagem representa claramente como o processo entre aproximação ao "novo", descritivismo nomenclatório e sentido da representação estão bem orientados para uma lógica totalmente utilitarista, vindo a formar um clímax que inverte, e revela, a perspectiva aparente até aqui mostrada nas imagens no texto, na função retórica que elas delineiam ${ }^{13}$. Estabelecido o primeiro contato, o relacionamento alarga-se a uma maior presença recíproca, que começa a definir com maior nitidez os seus contornos, tendendo a se estabilizar e se conformar num signo estável e não só, como por exemplo na precedente cena intermédia da construção do pavilhão para a celebração da missa, em formas rituais de representação. A fabricação de uma cruz, uma "grande cruz", obedece exatamente a esta lógica do processo retórico que, através da imagem, delimita, circunscreve o espaço ignoto e que se coloca como elemento discursivo (não dialógico, porque isso pressuporia uma igualdade dos sujeitos) de inter-relação com o "novo". Poderíamos afirmar que nos encontramos sempre perante um esquema hermenêutico de tipo vertical, hierárquico, piramidal, próprio da cultura e do imaginário dos conquistadores, que se contrapõe àquele horizontal e paratático, característico das culturas indígenas. São de notar, ademais, outros dois aspectos, relativos à representação dos indígenas: primeiro, o seu comportamento mimético, que é associado ao comportamento infantil, criando, assim, aquele curto-circuito semântico entre imaginário e real, entre perfeição esperada e pureza reencontrada, que levará à identificação inicial entre Novo Mundo e Éden; e sucessivamente a observação errônea (mas errônea, como se viu, apenas num contexto de percepção da relatividade cultural, que é sobretudo relatividade de símbolos, e portanto num contexto contemporâneo, e natural, pelo contrário, no contexto cultural de Caminha, e portanto dos conquistadores) segundo a qual a atenção e o interesse dos indígenas se dirigiam mais para os utensílios, para os objetos do fazer, do que para cruz, para o objeto a realizar (derivando disso, mais uma vez, uma incapacidade dos indígenas para a abstração do imediato e do contingente, não separada porém de uma atenção e de uma predisposição para a aprendizagem sempre positiva e confiante). É especialmente relevante, de fato (embora, talvez, casual nas intenções do autor), que o primeiro ato de participação dos indígenas em uma ação comum seja a fabricação da cruz. Outra casualidade não irrelevante é o fato de que o primeiro caso de desequilíbrio comunicativo entre conquistadores e indígenas se ligue precisamente à realização deste objeto 
tão fortemente simbólico, não apenas na economia e na finalidade interna do texto. A participação indígena na ação descrita - a fabricação de uma cruz, não se esqueça - assume dessa forma um grau tal que, eis a inversão final, o momento comum da relação, aquele que é definido através da ação "aconuersaçam" (a interpretar na acepção mais ampla de convívio, estar-se juntos, posto que a conversação estritamente verbal ainda estava num estádio embrionário), que deveria ser visto como um ato positivo, torna-se na realidade um impedimento, um obstáculo.

A visão do índio, com efeito, subjaz sempre a um ato de constante hibridação, em que o índio surge como figura que possui caracteres humanos e, repare-se, não animais, mas naturais, como se existisse uma indistinção entre índio e natureza, como se o índio existisse apenas como parte da natureza, como um ser proto-humano ou hetero-humano. É um mecanismo paradoxal, talvez a primeira verdadeira percepção do outro como tal, uma percepção que o afirma e o nega ao mesmo tempo, que reconhece a sua possível humanidade, mas a relega a uma esfera que não pertence ao humano, ou antes, que reconhece o humano como parte de um mecanismo, o natural, e não, como na visão europeia própria dos conquistadores, do homem como "intérprete/dominador" da natureza.

Quando saymos dobatel disse ocapitã que serja boo hirmos dereitos aacruz q estaua emcostada ahuua aruore junto com orrio perase poer de manhaã que he sesta feira e que nos posesemos todos em giolhos e abeijasemos pera eles veerem ho acatameto que lhe tijnhamos. e asy o fezemos. Eeses $\mathrm{x}$ ou xij [dez ou doze] que hy estauam acenaramlhes que fezesem asy e foram logo todos beijala. pareçeme jemte de tal jnoçencia que se os home emtendese e eles anos. que seriam logo xpaãos por que eles nõ teem nem emtendem em nhuua creemça $\operatorname{seg}^{\circ}$ pareçe. Epor tamto se os degradados que aqui am de ficar. aprenderem bem asua fala eos emtenderem. Nom doujdo seg ${ }^{0}$ asanta tençam de vosa alteza fazeremse xpaãos e creerem na nossa samta fé. aaqual praza anosso Sñor que os traga. por q çerto esta jente he boa e de boa sijnprezidade e enpremarsea legeiramete neeles qualqr cruno que lhes quiserem dar e logo lhes nosso $S^{\text {or }}$ deu boos corpos e boos rrostros comaaboos homees. e ele que nos per aquy trouue creo que nom foy sem causa e por tanto Vosa alteza pois tanto deseja acreçentar na santa fe catolica. Deue emtender em sua saluaçam e prazera ads que com pouco trabalho sera asy eles nõ lauram nem criam nem ha aquy boy nem vaca nem cabra nem ovelha nem $g^{a}$ nem out ${ }^{\mathrm{a}}$ nhua alimarea que custumada seja ao viuer dos homees ne come se nõ dese jnhame que aquy ha mujto e desa semente e frutos que atera e as aruores de sy lançam. e com isto andam taaes e tam rrijos e tã nedeos. queo nõ somosnos tamto com quanto trigo e legumes comemos. Em quanto aly este dia amdaram senpre ao soõ dhuu tanbory nosso dançarã e bailharã cõ os nosos. e maneira que sam muito mais nosos amjgos que nos seus. (CdA, p. 74) 
Esta longa passagem, apresentada na sua inteireza precisamente para mostrar a sua profunda unidade interna, encerra, numa progressão lógica exemplar, os vários momentos constitutivos do discurso hermenêutico de Caminha, que, nos limites impostos tanto pela formalidade quanto pela finalidade e pela extensão do texto, tenta propor-se, em todo caso, como um discurso crítico: a cruz como símbolo do poder religioso e real e a devoção a ela tributada, seguida de um convite aos indígenas à repetição do ato devocional, ou seja, a um ato mimético; a necessidade de compreender a língua indígena para poder comunicar, ou seja, para poder converter os indivíduos que demonstram uma inocência edênica e absoluta; a visão da ação de evangelização como necessária ação soteriológica; a definição da condição indígena como perfeito estado de natureza, contraposto à condição cultural europeia; a pureza e a simplicidade indígenas como seguras armas de submissão. E, com efeito, logo a seguir se lê:

Huu deles home de 1 ou lb [cinquenta ou cinquenta e cinco] anos ficou aly cõ aqueles que ficaram. aquele em nos asy estamdo ajumtaua aqueles que aly ficaram e ajnda chamaua outros. este andando asy antreles falando lhes acenou cõ odedo perao altar e depois mostrou odedo perao ceeo coma que lhes dizia alguua cousa debem e nos asy otomamos. [...] trazia njcolaao coelho mujtas cruzes de stanho com cruçufiços que lhe ficarom ajnda daoutra vijnda e ouuerã por bem que lancassem acada huu sua ao pescoço. pola qual cousa se asentou opadre frey anrique ao pee da cruz e aly ahuu ehuu lançaua sua atada em huu fio ao pescoço fazendolha primeiro beijar e aleuantar as maãos. Vijnhã aysso mujtos e lancarãnas todas que serjam obra de $\mathrm{R}$ ou 1 [quarenta ou cinquenta]. (CdA, p. 75-76)

A correspondência entre símbolo da divindade, o altar, e o seu lugar simbólico, o céu, é patente e compartilhada também pelos indígenas: o clímax da compreensão, da revelação que é compreensão, fica, portanto, completado. Da mesma forma ocorre com a coincidência entre o signo batismal (realizado não simbolicamente, com o ato lustral, mas fisicamente) e a cruz pendurada ao pescoço, fechando outro círculo de correspondência hermenêutica, que se torna, ela também, completa. E portanto, tal como se tomou posse da terra, primeiro através da denominação (Vera Cruz), segundo o esquema lógico clássico, pelo que nomear é criar e dominar, e sucessivamente pelo ato físico de elevação da cruz; do mesmo modo, pela mesma lógica retórica, a cruz pendurada ao pescoço dos indígenas marca, simultaneamente, um duplo processo, uma biunívoca correspondência: aquele do poder de submissão por parte dos portugueses sobre os indígenas e aquele, possivelmente mais importante por ser inesperado ( $\alpha \pi \rho \circ \sigma \delta o ́ \kappa \eta \tau o v$, que não se espera, ou seja, poderíamos dizer neste contexto, "achado"), do "reconhecimento", da aceitação por parte dos indígenas.

O artifício de Caminha que se revela no texto da Carta, portanto, parece mostrar, retoricamente, uma constante diminuição cognoscitiva (uma reductio ad notum): da vastidão da terra, da infinidade desconhecida 
e incomensurável, à mensurabilidade progressiva da ilha e depois da terra, à possibilidade de circunscrevê-la. A lógica hermenêutica consistirá sempre, como já se viu, numa aproximação negativa, isto é, no ato de tornar conhecido e familiar o que é desconhecido mediante afirmações negativas, afirmações que, mediante o processo de negação, afirmem a legibilidade do "novo". E o mecanismo de aplicação consistirá numa constante similitude demonstrativa, um "como em" contínuo: realiza-se uma espécie de encenação que desloca sempre o centro da ação do verdadeiro ato cognoscitivo, do contato, para o ato de mediação, de experiência, de tentativa para testar a reação, definindo dessa forma um conhecimento concessivo.

Agoas sam mujtas imfimdas. E em tal maneira he graciosa que querendoa aproueitar darsea neela tudo per bem das agoas que tem. pero omjlhor ftuito que neela se pode fazer me pareçe que sera saluar esta jemte e esta deue seer aprincipal semente que vosa alteza em ela deue lamçar. ( $C d A$, p. 77$)$

O processo, a estratégia retórica é definitivamente explicitada, as etapas da sua progressão lógica estão definidas: a inocência e a virgindade, a nudez como ausência de vergonha dos "seres encontrados", a riqueza infinita da terra, a difusão - "a principal semente" - do Verbo como difusão da potência real.

Assim, na fórmula de despedida final, serão especulares, de acordo com as regras clássicas, o deíctico "este" e o possessivo "vossa”, bem como simétrica é a correspondência Porto Seguro/Vera Cruz: "Deste porto seguro da vosa jlha de vera cruz oje sesta feira prim ${ }^{\circ}$ dia demayo de 1500 " (CdA, p.77).

Agora que a correspondência entre terra e soberano, a sua coincidência, é completa, a representação poderá ser, final e totalmente, descoberta.

\section{REFERÊNCIAS BIBLIOGRÁFICAS}

BARTHES, Roland. La retorica antica. $5^{\text {a }}$ ed. Milano: Bompiani, 2000. . Retorica dell'immagine. L'ovvio e l'ottuso. Saggi critici III. Torino, Einaudi, 1985, p. 22-41.

BECCARIA, Gian Luigi (org). Dizionario di linguistica e di filologia, metrica, retorica. Torino: Einaudi, 1996.

BERTOLUCCI PIZZORUSSO, Valeria. Uno spettacolo per il Re: l'infanzia di Adamo nella «Carta» di Pero Vaz de Caminha. Quaderni portoghesi. $\mathrm{n}^{\circ}$ 4, autunno 1978, p. 49-81.

FINAZZI AGRÒ, Ettore. Alle soglie del discorso coloniale: l'indio come frontiera nel Cinquecento. Letterature d’America, XIII, nº 51, 1993, p. 35-52. 

scoperta, le scoperte. Roma: Bulzoni, 2002, p. 21-36.

GENETTE, Gerard. Figure. Retorica e strutturalismo. Torino: Einaudi, 1969.

LAUSBERG, Heinrich. Elementi di retorica. Bologna: Il Mulino, 1969.

MORTARA GARAVELLI, Bice. Manuale di retorica. $4^{\text {a }}$ ed. Milano: Bompiani, 1999.

PEREIRA, Sílvio Baptista. Vocabulário da Carta de Pero Vaz de Caminha. Lisboa: Instituto Nacional do Livro, 1964.

PERELMAN, Chaïm; OLBRECHTS-TYTECA, Lucie. Trattato dell'argomentazione. La nuova retorica. Torino: Einaudi, 1989.

UNALI, Anna. La «Carta do achamento» di Pero Vaz de Caminha. Milano: Cisalpino- Goliardica, 1984.

\section{Recebido para publicação em 18/09/2015}

Aprovado em 19/01/2016

\section{NOTAS}

* Vicenzo ARSILlO é professor de Literatura Brasileira e Portuguesa (Departamento de Americanística, Iberística e Slavística) na Universidade Ca’ Foscari Veneza. Tem ensaios recentes sobre Miguel Torga, Eugénio de Andrade, José Cardoso Pires, José Saramago, António Lobo Antunes e João Guimarães Rosa. Integra o conselho da revista Letterature d'America, dirigida, em Roma, por Ettore Finazzi-Agrò.

2 Cfr. as fundamentais considerações desenvolvidas por Ettore Finazzi Agrò no ensaio "Alle soglie del discorso coloniale: l'indio come frontiera nel Cinquecento" (1993); e os aprofundamentos, igualmente significativos, do ensaio "Il principio in assenza. Il ruolo pre-liminare dell'indio nella cultura brasiliana” (2002).

3 Além da Carta de Caminha, a carta do Mestre João e a "Relazione del Pilota Anonimo".

4 "Non manca infine la dichiarazione programmatica di riferire esclusivamente su quanto accertato con i propri occhi - aquilo que vy e me pareceo -, senza intenzione di abbellire o svalutare (por afremosentar nem afear); ma si noti subito che questo motivo topico della produzione etno-geografica antica e in particolare della relazione di viaggio - e non della lettera che si deve presumere veridica -, è assunto qui nel tipo ridotto, che è molto più raro e che privilegia il primo elemento della formula tradizionale («per vista e per udita» nella sua integrità). Ciò sarà da tener presente quando se ne registrerà l'applicazione più rigorosa non solo come criterio di scelta dei referenti da mettere a testo, ma anche come principio esclusivo di costruzione e di montaggio del racconto caminhano" (Bertolucci Pizzorusso, 1978, p. 55). E, um pouco mais adiante, observa-se ainda: “[...] la conoscenza di esso [mondo] si realizza esclusivamente attraverso il canale ottico: il testo non registra altro che quello che un occhio vede, rifiutandosi di accogliere quanto non passi per esso: così ad es. quello che accade sulla spiaggia quando lo scrittore, cui questo sguardo ovviamente appartiene, sia costretto a restare sulla nave. Esso funziona dunque come un obbiettivo mobile, che segue e riprende uno spettacolo, l'azione scenica in cui si trasforma di conseguenza la vicenda di un approccio tra due diversi gruppi umani, divisa in tanti quadri quanti ne esigono le precise indicazioni [...] delle unità di tempo" (ibidem, p. 58). 
5 "Perché si abbia una figura, sembrano indispensabili due caratteristiche: una struttura distinguibile, indipendente dal contenuto, cioè una forma (sia essa, secondo la distinzione dei moderni cultori di logica, sintattica, semantica o pragmatica) e un uso che si allontani dal modo normale di esprimersi, e attiri così l'attenzione. Almeno una di queste esigenze si ritrova nella maggior parte delle definizioni di figure, proposte nel corso dei secoli; l'altra si introduce in esse indirettamente" (Perelman; Olbrechts-Tyteca, 1989, p. 177). Ver-se-á, porém, que na Carta do achamento é mesmo a persistência de algumas figuras a determinar o seu desvio da norma e a constituir, dessa forma, a evidência das mesmas: um uso constante da norma produzirá, por outras palavras, um efeito estranhante face ao próprio discurso em que se insere.

6 "L'esordio comprende canonicamente due momenti. I. La captatio benevolentiae, impresa di seduzione nei confronti degli ascoltatori, che si tratta di conciliarsi subito con una prova di complicità. La captatio è stata uno degli elementi più stabili del sistema retorico (essa fiorisce ancora nel Medioevo ed anche ai giorni nostri); [...] II. La partitio, secondo movimento dell'esordio, annuncia le ripartizioni che si stanno per adottare, il piano che si sta per seguire (si possono moltiplicare le partitiones, metterne una all'inizio di ciascuna parte); il vantaggio, dice Quintiliano, è che non si trova mai troppo lungo quello di cui si annuncia il termine" (Barthes, 2000, pp. 92-93).

7 Doravante, este texto será referido como $C d A$.

\section{Ibidem.}

9 "In fondo la descriptio rerum non lo interessa in sé, ma soltanto in rapporto alluomo, come dimostrano lo sviluppo, relativamente notevole, dato alla descrizione delle abitazioni degli indigeni e del loro corredo interno (le amache), e le frequenti carrellate sul paesaggio in quanto ambiente di vita dell'uomo «nuovo», esaltato nelle sue «infinite» acque, marine e terrestri: la marea, che con la sua forte escursione lascia scoperte e pescose le spiagge, i fiumi ricchi d'acqua, le lagune, l'isolotto, i grandi banchi di argille bianche e rosse; le foreste a perdita d'occhio delle più svariate specie di alberi, popolate da uccelli variopinti, i palmeti fruttiferi, le radici commestibili" (Bertolucci Pizzorusso, 1978, p. 60).

\section{Itálico nosso.}

\section{Itálico nosso}

12 "Os outros dous queo capitã teue nas naaos aque deu oque ja dito he. numca aqui mais pareçeram. de que tiro seer jente bestial e depouco saber e por ysso sam asy esqujvos. eles porem cõ tudo andam mujto bem curados e mujto limpos e naquilo me pareçe ajmda mais que sam coma aves ou alimareas monteses que lhes faz ho aar mjlhor pena e mjlhor cabelo que aas mansas. porque os corpos seus sam tam limpos e tam gordos e tam fremosos que nõ pode mais ser. e jsto me faz presumir que nõ teem casas ne moradas em que se colham eo aar aque se criam os faz taaes. ne nos ajnda ataagora nom vimos nehuuas casas nem maneira delas" ( $C d A$, p. 70).

13 "Secondo un'etimologia antica, la parola immagine dovrebbe venir collegata alla radice di imitari. Eccoci di colpo nel cuore del problema più importante che può presentarsi alla semiologia delle immagini: la rappresentazione analogica (la «copia») può produrre veri sistemi di segni o soltanto agglutinazioni di simboli? Un «codice» analogico - e non più digitale - è concepibile? Si sa che i linguisti allontanano dal linguaggio ogni comunicazione per analogia, dal «linguaggio» delle api al «linguaggio» gestuale, in quanto tali comunicazioni non sono doppiamente articolate, cioè fondate in definitiva su una combinatoria di unità digitali, come i fonemi. I linguisti non sono i soli a nutrire sospetti verso la natura linguistica dell'immagine; anche lopinione comune intende confusamente l'immagine come un luogo di resistenza al senso, in nome di una certa idea mitica della Vita: l'immagine è ri-presentazione, cioè in definitiva resurrezione, e si sa che l'intellegibile è ritenuto ostile al vissuto. Così, dai due lati, l'analogia è considerata come un senso povero: gli uni pensano che l'immagine sia un sistema molto rudimentale in rapporto alla lingua, gli altri che la significazione non possa esaurire la ricchezza ineffabile dell'immagine. Ora, anche e soprattutto se l'immagine è in certo modo un limite del senso, è ad unautentica ontologia del senso che essa permette di ritornare. In che modo il senso giunge all'immagine? Dove finisce il senso? E se finisce, che cosa cè al di là? È il problema che si vorrebbe porre qui, sottoponendo l'immagine a unanalisi spettrale dei messaggi che essa può contenere" (Barthes, 1985, p. 22-23). 